\title{
Clinical Comparative Study between Fentanyl and Dexmedetomidine with Bupivacaine for Lower Limb Surgery in Spinal Anaesthesia
}

\author{
Tuhin Vashishth ${ }^{1}$, Sangeeta Varun ${ }^{2}$ \\ ${ }^{1}$ Associate professor, Department of Anaesthesia, LLRM Medical College Meerut, U.P, India, ${ }^{2}$ Assistant professor, Department of Anaesthesia, LLRM \\ Medical College Meerut U.P, India.
}

\section{Abstract}

Background: Spinal anesthesia is a preferred technique of choice in infra umbilical surgeries. The spinal anesthesia effect can be improved by adding various adjuvant like Fentanyl, clonidine, dexmedetomidine. Dexmedetomidine is a highly selective alpha 2 adrenergic agonists. The aim of study to compare efficacy and safety between Dexmedetomidine and Fentanyl with Bupivacaine. Subjects and Methods: A prospective randomized, double-blind study was conducted on 100 patient by dividing them into two groups. Group D: $2.5 \mathrm{ml}$ (12.5mg) of $0.5 \%$ hyperbaric bupivacaine with $5 \mathrm{mcg}(0.5 \mathrm{ml})$ dexmedetomidine and Group $\mathrm{F}: 2.5 \mathrm{ml}(12.5 \mathrm{mg})$ of $0.5 \%$ hyperbaric bupivacaine with 2 $5 \mathrm{mcg}(0.5 \mathrm{ml})$ fentanyl. The total volume injected intrathecally was $3.0 \mathrm{ml}$ in ASA I and II grade patient undergoing lower limb surgery. Results: Patients in dexmedetomidine group D had a significantly longer sensory and motor block time than patients in fentanyl group F. The mean time of sensory regression to level S1 was 306.00 \pm 13.32 in group D and 206.14 \pm 16.69 in group $F(P<0.001)$. The regression time of motor block to reach modified Bromage 0 was $257.70 \pm 14.61$ in group $\mathrm{D}$ and $178.54 \pm 14.23$ in group $\mathrm{F}$ ( $\mathrm{P}<0.001)$. Conclusion: Intrathecal Dexmedetomidine is associated with prolonging motor and sensory block as compare to Fentanyl.

Keywords: Bupivacaine, Dexmedetomidine, Fentanyl, spinal anesthesia.

Corresponding Author: Dr. Sangeeta Varun, Assistant Professor, Department of Anaesthesia, LLRM Medical College Meerut, U.P, India. Email: drtuhinv@gmail.com

Received: April 2020

Accepted: April 2020

\section{Introduction}

Spinal anaesthesia is most commonly used for infra umbilical surgeries. The spinal block has a rapid onset, deep block and cost-effectiveness. However, postoperative pain is an important problem as the use of the drug has limited duration of effect, so the administration of the postoperative analgesic is necessary. ${ }^{[1,2]}$

Administrating the combination of other classes of analgesics with local anaesthetics has used to increase the duration and reduce the side effects of analgesia. ${ }^{[3]}$ Various additive drug have been tried with Bupivacaine for improvement in the quality and extending the duration of blockade like vasoconstrictors, opioid analogs, neostigmine, benzodiazepine, ketamine and $\alpha 2$ agonist etc. ${ }^{[4,5]}$ Opioid analogs as an additive in spinal anaesthesia improve the onset of action to prolong the duration of block and to improve the quality of intraoperative and postoperative analgesia. ${ }^{[4-6]}$ Dexmedetomidine belongs to the imidazole subclass of $\alpha 2$-receptor agonist similar to clonidine and FDA approved used as a sedative in ICU patients also used as anxiolysis, hypnosis, sympatholytic and adjunct analgesia. ${ }^{[7,8]}$ Dexmedetomidine potentiates the effect of all intraoperative anesthetics regardless of method of administration(intravenous, volatile or even regional block. ${ }^{[9,10]}$

Fentanyl is a lipophilic opioid that has a rapid onset and short duration of action following intrathecal administration. It prolongs the duration and reduced analgesic requirements in the early postoperative period following spinal block. ${ }^{[4]}$

In this study our aim to compare the efficacy of dexmedetomidine and Fentanyl added to intrathecal Bupivacaine in terms of duration of block and analgesia in lower limb surgeries.

\section{Subjects and Methods}

After approval from the institutional ethical committee, 100 patients, aged 18 to 60 years, of either sex, undergoing lower limb surgery and belonging to American society of anesthesia (ASA) class 1 or 2, who visited the institution from November 2016 to October 2017 were screened for the study. A thorough pre-anesthetic checkup, including a detailed history and physical examination, was done. Patients having any major cardiovascular, neurological or respiratory illness were excluded from the study. Other exclusion criteria were any vertebral deformity or history of trauma to spine, skin infection at the site of lumbar puncture, any contraindication to spinal anaesthesia and patient's refusal for the procedure.

The patients were explained about the procedure and about 
visual Analogue Scale (VAS). Informed consent was taken. The patients were kept fasting as per standard guidelines. They were premedicated with Alprazolam $0.25 \mathrm{mg}$ and Ranitidine $150 \mathrm{mg}$ orally the night before and on the morning of surgery.

The randomization was done using a computer-generated sequence of numbers and the sealed envelop technique. The 100 patients were randomly divided into two groups.Group $\mathrm{D}$ received $2.5 \mathrm{ml}$ hyperbaric bupivacaine $0.5 \%(12.5 \mathrm{mg})$ with $5 \mathrm{mcg}(0.5 \mathrm{ml})$ of inj. Dexmedetomidine (total volume $3.0 \mathrm{ml}$ ). Group $\mathrm{F}$ received $2.5 \mathrm{ml}$ of hyperbaric bupivacaine $0.5 \%(12.5 \mathrm{mg})$ with $25 \mathrm{mcg}(0.5 \mathrm{ml})$ fentanyl (total volume $3 \mathrm{ml}$ ). An independent anesthesiologist prepared the drug under all aseptic precaution in similar disposable syringes and was not involved in further management or observation of the patients. The person performing the spinal anesthesia had no knowledge about the content of the syringes.

In the operation room, standard monitoring includes 5 lead electrogram, noninvasive automated blood pressure and pulse oximetry done. Baseline heart rate, blood pressure, respiratory rate and hemoglobin oxygen saturation were recorded. An $18 \mathrm{G}$ cannula was secured into a peripheral vein and $15 \mathrm{ml} / \mathrm{kg}$ body weight lactated Ringer solution was administered. The patient was placed in a sitting position on the operation table with stool provide as a footrest and pillow placed in the lap. An assistant maintained the patient in a vertical plane while flexing the patient's neck and arms over the pillow to open the lumber interspinous space. With full aseptic precaution, intervertebral space between L3-L4 vertebra was identified and a small skin wheal was raised with $3 \mathrm{ml}$ of lignocaine 2\%. A 25G Quincke spinal needle was inserted, advanced and subarachnoid space recognized. The study drug was administered at a rate of $0.2 \mathrm{ml} / \mathrm{second}$. The patient was placed in a supine position until the maximum effect was achieved.

After assessing the time of onset of action of drug and level of blocked, the surgery was allowed. The level of sensory blockade was assessed by pinprick using a short bevel needle while the patient's eyes were covered. The parameters observed included time of onset of sensory blockade(time between administration of drug and onset of tingling and numbness in the lower limb), degree of motor blockade tested by James Modified Bromage score ${ }^{11}[0=$ unable to raise leg straight against resistance, $1=$ unable to raise leg straight but able to flex the knee, $2=$ unable to flex knee but with free movement of feet, $3=$ unable to move leg or feet], duration of analgesia( time from administration of an intrathecal drug to very first complain of pain). The heart rate, blood pressure, oxygen saturation and respiratory rate were also recorded. All the parameters were recorded just after giving spinal anaestyhesia ( $0 \mathrm{~min})$, then at $5 \mathrm{~min}$ intervals till 15 minutes, after that $15 \mathrm{~min}$ intervals till $180 \mathrm{~min}$. A drop in heart rate below 60 beats/min was managed with atropine $0.2 \mathrm{mg}$ increment iv was given, and a fall in blood pressure $\geq 20 \%$ of baseline was initially managed with a bolus of $5 \mathrm{ml} / \mathrm{kg}$ of lactated Ringer solution, followed by inj. Ephedrine 6mg bolus increment iv. Oxygen 3-4 lit/min was given with face mask if spo 2 fell below $94 \%$. If the respiratory movement were paradoxical or the patient complained of dyspnoea and oxygen saturation could not be maintained with the abovementioned measures, respiratory assistance was given with or without endotracheal intubation.

When the patients VAS score was $>3$, analgesia was supplemented with $1 \mathrm{mg} / \mathrm{kg}$ of tramadol iv. Any side effects like sedation, respiratory depression, nausea, vomiting, pruritus, urinary retention were recorded.

\section{Statistical Analysis}

The statistical analysis was done using SPSS for window version 15.0 software. Data are presented as median, mean $( \pm \mathrm{SD})$ or frequencies as appropriate. Statistical tests applied included student t-test, two-tailed Mann-Whitney $\mathrm{u}$-test. Pvalue $<0.05$ was considered statistically significant.

\section{Results}

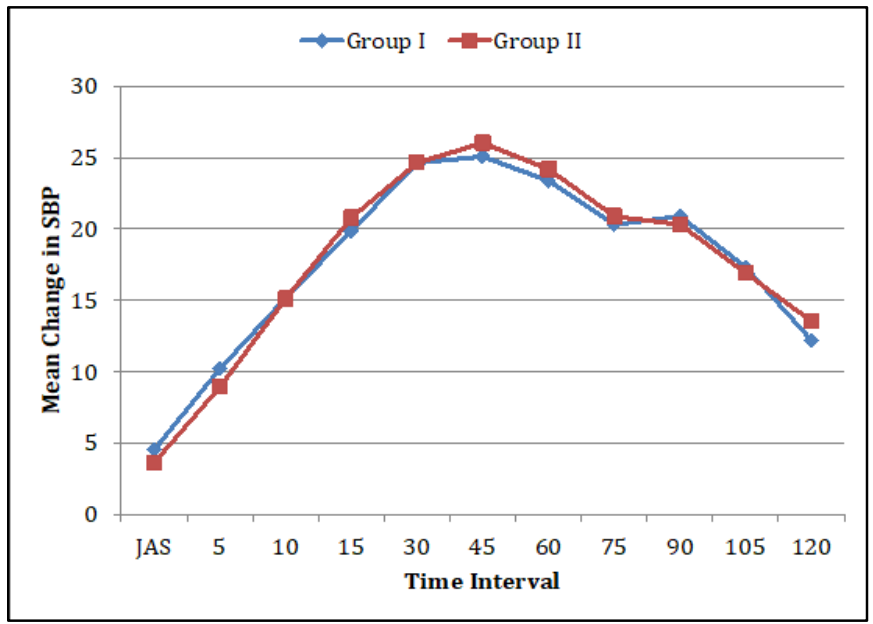

Figure 1: mean change in SBP in 2 groups

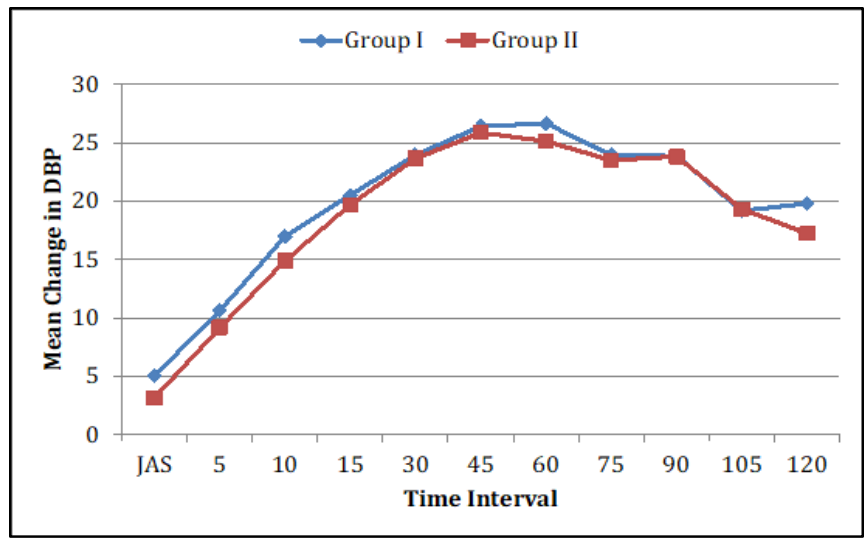

Figure 2: mean change in DBP in 2 groups

There was no significant differences between the two age group regarding age, weight, height and sex. There was no significant difference in the type and duration of surgery. Intraoperative systolic, diastolic and mean arterial blood pressure trends are shown in [Figure 1-3]. Heart rate trends are shown in [Figure 4].

Mean oxygen saturation in both groups shown in [Figure 5]. The following conclusions were drawn from the study. Meantime of onset of sensory block (T10) for group D and group $\mathrm{F}$ were $3.72 \pm 0.50$ minutes and $3.80 \pm 0.53$ minutes, respectively. The onset of sensory block was faster in group D. There for showing statistically significant intergroup difference $(\mathrm{p}<0.001)$ but no significant difference between 
group $\mathrm{D}$ and $\mathrm{F}(\mathrm{p}=0.440)$. The median level of sensory block was T6 in all two groups after $15 \mathrm{~min}$ of intrathecal injection of drugs. The mean time to achieve T6 sensory block was significantly lower in group D $(<0.001)$. All patients achieved a maximum grade of motor blockade showing no significant difference between two-groups $(\mathrm{p}=1)$. Meantime to achieve grade III motor in group D 5.76 \pm 0.43 and group F were $5.80 \pm 0.40$. The onset of motor block was faster in group $\mathrm{D}(\mathrm{P}=<0.001)$, showing a statistically significant intergroup difference but no significant between study group $\mathrm{D}$ and $\mathrm{F}(>0.05)$. The time period for sensory regression to S1 level were $306.0 \pm 13.32,206.14 \pm 16.69$ minutes in study group $\mathrm{D}$ and $\mathrm{F}$, respectively. Sensory block regression to $\mathrm{S} 2$ is faster in group $\mathrm{F}$ as compared to group $\mathrm{D}(\mathrm{p}<0.001)$. The time period of recovery of motor block was more in group D $257.70 \pm 14.61$ in comparison to group F $178 \pm 14.23$ minutes. The mean duration of analgesia was in group D 373.0 \pm 16.26 and 302.40 16.01 in group $\mathrm{F}$ minutes showing significant difference among two groups $(\mathrm{p}<0.001)$. Although the patients in both groups remained hemodynamically stable intraoperatively. No significant difference was observed among both groups for side effects. Sedation was more in group D. Hypotension and bradycardia more in group $\mathrm{F}$ followed by group D. No patients have nausea vomiting and respiratory depression in groups in both the group.

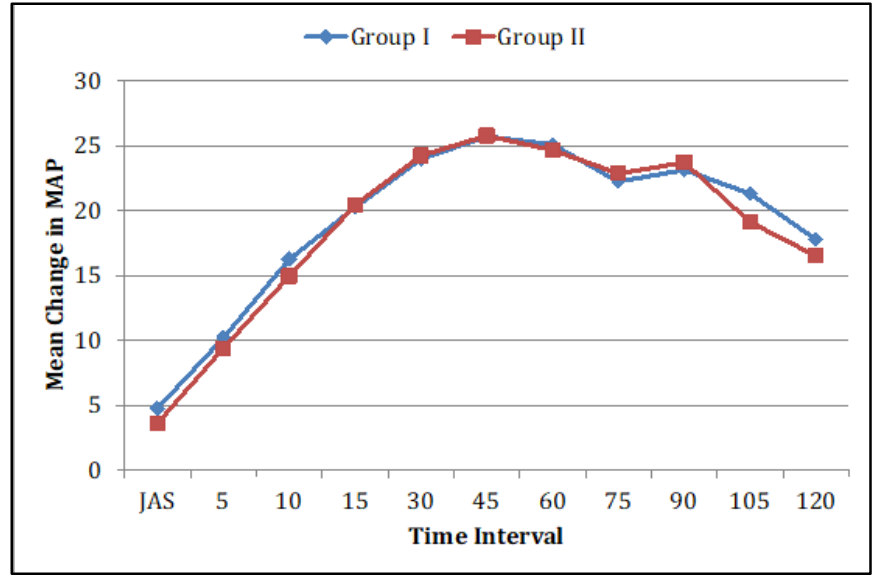

Figure 3: mean change in MAP in 2 groups

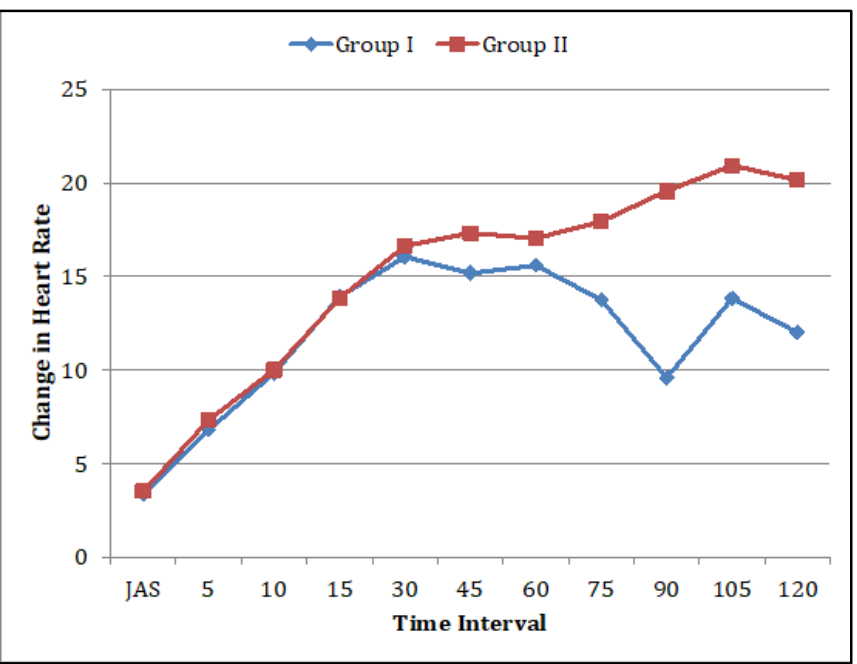

Figure 5: mean change in heart rate in 2 groups

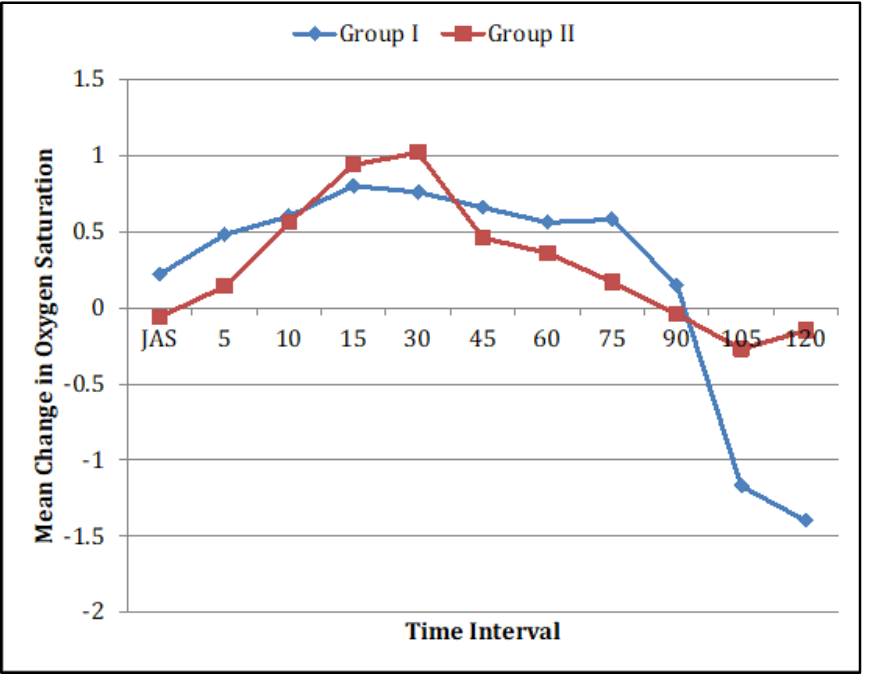

Figure 5: mean change in oxygen saturation in 2 groups

\section{Discussion}

The mechanism by which intrathecal $\alpha 2$ adrenoceptor agonists prolong the motor and sensory block of local anesthetic is not well known. They act by binding to presynaptic C- fibers and postsynaptic dorsal horn neurons. Their analgesic action is a result of depression of the release of $\mathrm{C}$ - fiber transmitter and hyperpolarisation of postsynaptic dorsal horn neurons. ${ }^{[12]}$

Alpha 2 adrenergic receptor agonists like clonidine and dexmedetomidine have been the focus of interest for their sedative, analgesic, sympatholytic and hemodynamic stabilizing properties. Clonidine has been used intrathecally to prolong the sensory and motor block and reduced tourniquet pain. It prolongs and intensified the effect of the spinal anesthetic by altering systemic resorption. Dexmedetomidine is a newer, highly selective drug in the same family, with a different, more favorable pharmacokinetic profile. The analgesic property of dexmedetomidine is $8-10$ fold more than clonidine. It has been recently used as a systemic analgesia and regional anesthesia adjuvant, both intrathecal and epidural to intensify and prolong the action of analgesic and local anesthetics. ${ }^{[13-15]}$

Opioid analogs have been used as an additive in spinal anesthesia to improve the onset of action to prolong the duration of block and to improve the quality of intraoperative and postoperative analgesia. ${ }^{[4-6]}$

In the present study mean time to achieve sensory block, the duration of sensory block and the meantime is taken for regression to $\mathrm{S} 1$ segment was statistically significant with a p-value of $<0.001$ in group D in comparison to group F. Gupta et al, ${ }^{[15]}$ who compared $5 \mathrm{mcg}$ Dexmedetomidine and $25 \mathrm{mcg}$ of fantasy with Bupivacaine intrathecally found a significant change in dexmedetomidine droup with regard to time of onset, duration, and time is taken for regression to $\mathrm{S} 1$ segment. Fyneface-Ogun et $\mathrm{al}^{[16]}$ used dexmedetomidine $2.5 \mathrm{mcg}$ intrathecally found significant change in time to achieve the highest sensory block and time taken for regression to S1 when compared to Fentanyl.

The mean time is taken for the onset of Bromage 3 in group $\mathrm{D}$ and group $\mathrm{F}$ were comparable. The mean time taken for 
regression to Bromage 0 in group D was statically significant with a p-value of $<0.001$. Similar results were found in the study of Gupta et al. ${ }^{[15]}$ Al-Mustafa et al, ${ }^{[17]}$ who used varying doses of dexmedetomidine, found a statistically significant change in the onset of Bromage 0 .

The duration of analgesia is prolonged in the dexmedetomidine group when compared to Fentanyl. The mean time for rescue analgesia was significantly higher with dexmedetomidine. There is a wide variation in time for first rescue analgesia in dexmedetomidine and fentanyl group in various studies of Gupta et al, ${ }^{[15]}$ Eid et al, ${ }^{[18]}$ and Jamliya et al. ${ }^{[19]}$ But dexmedetomidine produced prolonged analgesia when compared to Fentanyl, which was statistically significant in all the studies.

Intrathecal Dexmedetomidine and Fentanyl with Bupivacaine did not have much effect on vital parameters except for a decrease in heart rate in the dexmedetomidine group. A similar observation was made by Mohammed et al. ${ }^{[20]}$ Patients in both groups were hemodynamically stable as shown in the study of Gupta et al, ${ }^{[15]}$ Al-Mustafa et al, ${ }^{[17]}$ and Tarbeeh et al, ${ }^{[21]}$ did not find much change between the groups.

No significant difference was observed among the different groups for the side effects sedation was more in groups D than groups $\mathrm{F}$.

\section{Conclusion}

In our study comparing intrathecal Dexmedetomidine and intrathecal Fentanyl with Bupivacaine, the result indicate that dexmedetomidine provides mean time to achieve sensory and motor block was shorter in the dexmedetomidine groups. The median of the maximum level of sensory block was the same in both the groups. The sensory and motor block was more prolonged in dexmedetomidine groups than fentanyl groups showing a significant difference among the two groups $(p<0.001)$. The overall duration of analgesia was significantly longer in dexmedetomidine groups than fentanyl groups showing a significant difference among the two groups $(\mathrm{p}<0.001)$.

We conclude that dexmedetomidine may find a place in regular clinical use as an intrathecal adjuvant with hyperbaric Bupivacaine due to its improved quality of sensory and motor block characteristics when compared to Fentanyl. Hence dexmedetomidine may be used as an alternate to Fentanyl for intrathecal use.

\section{References}

1. Elia N, Culebras X, Mazza C, Schiffer E, Tramer MR. Clonidine as an adjuvant to intrathecal local anaesthetics for surgery: systematic review of randomized trials. Reg Anesth Pain Med. 2008;33(2):159-67

2. Boussofara M, Carles M, Raucoules -Aime M, Sellam MR, Horn JL. Effects of intrathecal midazolam on postoperative analgesia when added to a bupivacaine-clonidine mixture. Reg Anesth Pain Med. 2006;31(6):501-5

3. Faiz SH, Rahimzadeh P, Sakhaei M, Imani F, Derakhshan P. Anaesthetic effects of adding intrathecal neostigmine or magnesium sulphate to Bupivacaine in patients under lower extremities surgeries. J Res Med Sci. 2012;17(10):918-22.

4. Singh $\mathrm{H}$, Yang $\mathrm{J}$. intrathecal Fentanyl prolongs sensory bupivacaine spinal block. Can J Anesth.1995;42:987-91.

5. Jaishribogra. Synergistic effect of intrathecal Fentanyl and Bupivacaine in spinal anesthesia; BMC Anesthesiology. 2005;5:5-12.

6. Biswas BN. Intrathecal Fentanyl with Hyperbaric Bupivacaine improves analgesia during Caeserian delivery and in early postoperative period. Indian J Anaesthesia.2002;46(6):469-472.

7. Venn RM, Bradshaw CJ, Spencer R, Brealey D, Caudwell E, Naughton C, Vedio A, Singer M, Feneck R, Treacher D, Willatts SM, Grounds RM. Preliminary UK experience of dexmedetomidine, a novel agent for postoperative sedation in the intensive care unit. Anaesthesia 1999;54:1136-1142.

8. Martin E, Ramsay G, Mantz J, Sum-PMG St. The role of the $\alpha 2$ adrenoreceptor agonist. Dexmedetomidine in postsurgical sedation in the intensive care unit-I. Intensive care:Med 2000;18: 29-34.

9. Antaa R. Jaakola ML, Kallio A, Kanto J. Reduction of MAC of isofluranece by dexmedetomidine. Anaesthesiology. 1997;86: 10551066.

10. Burher M, Mappes A, Louber R, Stanski DR, Maitre PO. Dexmedetomidine decreases thiopental dose requrirement and alter distribution pharmacokinetics Anesthesiology 1994; 80: 1216-1227.

11. Fettes PD, Hocking G, Peterson MK, Luck JF, Wildsmith JA. Comparison of plain and hyperbaric solution of ropivacaine for spinal anaesthesia. Br J Anaesth 2005;94:107-11.

12. Eisenach JC, De Kock M, Klimscha W.o2- Adrenergic Agonist for Regional Anesthesia: A Clinical Review of Clonidine (1984-1995). Anesrhesiology. 1996;85:655-74.

13. Pitkanen M. Techniques of Neural Blockade in Clinical Anesthesia in Cousins and Brindenbaugh's Neural Blockade in clinical Anesthesia and pain Medicine. Cousins MJ Editor. 4th edition. Lippincott Williams and Wilkins China;2009:216-217

14. Al- Ghanem S, Massad I M, Al-Mustafa M M, Khaled R Al- Zaben, Ibrahim Y Qudaisat, Ayman M Qatawneh, Hamdi M Abu -Ali. Effect of addind Dexmedetomidine versus Fentanyl to intrathecal Bupivacaine on spinal block characterstics in gynaecological procedures: A double blind controlled study. Am J App Sci 2009;6(5):882-887.

15. Gupta R, Bogra J, Verma R, Kohli M, Kushwaha JK, Kumar S. Dexmedetomidine as an intrathecal adjuvant for postoperative analgesia. Indian J Anesth 2011;55(4):347-351.

16. Fyneface-Ogan S, Job OG, Enyindah CE. Comparison effect of single shot intrathecal Bupivacaine with Dexmedetomidine and Bupivacaine with Fentanyl on labour outcome. ISRN Anesthesiol. 2021;2012:1-6.

17. Al -Mustafa M M, Abu-Halaweb S A, Aloweidi A S, Mursbidi M M , Ammari B A, Awawad Z M et al. Effect of Dexmedetomidine added to spinal Bupivacaine for urological procedures. Saudi Med J 2009;30(3):365-370.

18. Eid HEA, Shafie MA, Youssef H. Dose-related prologation of hyperbaric Bupivacaine spinal anesthesia by dexmedetomidine. Ain Shams J Anesthesiol. 2011;4(2):83-95.

19. Jamliya RH, Desmukh V, Rajesh $C$, et al. effect of adding dexmedetomidine in intrathecal Bupivacaine versus intrathecal Bupivacaine alone on spinal block characteristics in orthopaedics lower limb procedures [A Comparative study]. RJPBCS 2013;4(1):1340-6.

20. Mohamed MA, Fares KM, Mohamed SA. Efficacy of intrathecally administered Dexmedetomidine versus Dexmedetomidine with Fentanyl in patients undergoing major abdominal cancer surgery. Pain physician 2012:15:339-348.

21. Tarbeeh GA, Mohamed AA. Effect of intrathecal Bupivacaine Fentanyl versus bupivacaine-dexmedetomidine in diabetic surgical patients. Egypt J Anaesth 2013;29:13-18. 
Copyright: (C) the author(s), 2020. It is an open-access article distributed under the terms of the Creative Commons Attribution License (CC BY 4.0), which permits authors to retain ownership of the copyright for their content, and allow anyone to download, reuse, reprint, modify, distribute and/or copy the content as long as the original authors and source are cited.

How to cite this article: Vashishth T, Varun S. Clinical Comparative Study between Fentanyl and Dexmedetomedine with Bupivacaine for Lower Limb Surgery in Spinal Anaesthesia. Acad. Anesthesiol. Int. 2020;5(1):126-130.

DOI: dx.doi.org/10.21276/aan.2020.5.1.25

Source of Support: Nil, Conflict of Interest: None declared. 